\title{
«Gobernar el Mundo». La polémica Mare Liberum versus Mare Clausum en las Indias Orientales (1603-1625)/
}

\author{
«Governing the World». The Mare Liberum vs. Mare Clausum \\ Polemic in the East Indies (1603-1625)
}

\author{
José Antonio Martínez Torres \\ ORCID iD: http://orcid.org/0000-0003-3042-6662 \\ Universidad Nacional de Educación a Distancia, Madrid
}

La captura en 1603 de la nave portuguesa Santa Catarina por los marinos holandeses de la Compañía de las Indias Orientales (1602) en el océano Índico, dio origen a una disputa político-intelectual por la libertad y el dominio del mar que enfrentó a algunos de los mejores publicistas de Holanda (Hugo Grocio) y de la Monarquía Hispánica (Serafín de Freitas). Esta controversia, que hunde sus raíces en el derecho romano y en la filosofía de la segunda escolástica española, tuvo especial trascendencia en Europa en el primer tercio del siglo XVII y algunos años después.

Palabras Clave: Hugo Grocio; Serafín de Freitas; Comercio; Indias Orientales; República de Holanda;

Monarquía Hispánica; Mare Liberum; Mare Clausum.

In 1603, the Dutch captured the Portuguese ship Santa Catarina in Southeast Asia. Consequently, a contentious intellectual debate over the freedom and dominance of the sea ensued. The dispute pitted against each other some of the most notable publicists from Holland and the Spanish Monarchy, including Hugo Grotius and Serafin de Freitas. This controversy had great significance in Europe during seventeenth century and beyond.

Keywords: Hugo Grotius: Serafín de Freitas; Trade; East Indian; Dutch Republic; Spanish Monarchy; Mare Liberum; Mare Clausum.

Copyright: (C) 2017 CSIC. Este es un artículo de acceso abierto distribuido bajo los términos de una licencia de uso y distribución Creative Commons Attribution (CC-by) España 3.0.

* Este trabajo ha sido realizado en el marco de los siguientes proyectos de investigación: RYC 2011-08053, HAR 2012-37560-C02-01, HAR 2013-42300-P. Agradezco las observaciones efectuadas a una primera versión de este trabajo por: Carlos Martínez Shaw, José María Iñurritegui Rodríguez, Sir John H. Elliott y Pablo Fernández Albaladejo. Asimismo, estoy en deuda con los incisos y advertencias que hicieron los anónimos evaluadores de esta revista. 
Aquel que domine los mares dominará el mundo, y quien domine el comercio en el mundo gobernará en sus riquezas y, por tanto, en el propio mundo. ${ }^{l}$

\section{Introducción}

Estas palabras tan clarividentes y materialistas, escritas por ese relevante marino, cosmógrafo y aventurero inglés que fue Sir Walter Raleigh (1554-1618), paradójicamente una de las personas que más empeño puso por encontrar la mítica región de El Dorado al sur del continente americano, son un reflejo fiel de los rápidos y trascendentales cambios que se estaban produciendo en el universo político e intelectual europeo de principios del siglo XVII de resultas del apresamiento de la carraca portuguesa Santa Catarina $^{2}$ por el almirante holandés Jacob van Heemskerk (1567-1607). Tal hecho, que se produjo el 25 de febrero de 1603 en un lugar impreciso de la ruta mercantil lusa que unía Malaca y Goa, en cierto modo resultó legitimado por Hugo Grocio (1583-1645) en un amplio tratado titulado De iure praedae, ${ }^{3}$ cuya finalidad era convencer, ante el Tribunal de Presas de Holanda, al poderoso lobby de accionistas mennonitas de la recién fundada Compañía de las Indias Orientales (Vereenigde Oostindische Compagnie, o VOC) (1602), que dudaban si había que aceptar o no las ganancias obtenidas en este apresamiento (3.389.772 florines de la época), reprobable en opinión de muchos de ellos porque, además de ir en contra de su principal precepto religioso (las acciones violentas eran repudiadas por el conjunto de la comunidad mennonita), posibilitaba que otras potencias marítimas emergentes (Inglaterra sobre todo) efectuaran actos semejantes contra los intereses mercantiles neerlandeses en sus enclaves y factorías en el Brasil, las costas del continente africano y el sudeste asiático. ${ }^{4}$

1 Raleigh, 1667 [1650], 20.

2 El porte de la nave era de 1.500 toneladas. Además de un rico y variado cargamento compuesto de plata amonedada, tejidos de seda y algodón, porcelanas finas y jade, la carraca Santa Catarina también llevaba 750 personas a bordo, de las que 100 eran mujeres y niños.

3 Él mismo Grocio, primo de Van Heemskerk, solía llamar a este trabajo De rebus indicis opusculum. Probablemente jamás hubiéramos tenido noticia de tal texto si no hubiera sido identificado, prácticamente por azar, por un atento bibliófilo que rastreaba obras de Grocio en el catálogo de una venta de manuscritos antiguos que tuvo lugar en La Haya en 1864. La conmoción que causó entre los expertos en la materia el hallazgo de este trabajo fundamental queda patente en su inmediata publicación, cuatro años después de haberse encontrado, en una modélica edición que todavía sigue siendo útil a los estudiosos (véase Grocio, 1868). Sobre esta particular peripecia informan: Pauw, 1965. Roelofsen, 1992. Ittersum, 2006. Borschberg, 2011.

4 Ittersum, 2003; 2009a; 2009b; 2010. Gelderen, 2004. 
Sea como fuere, lo cierto es que las principales autoridades holandesas decidieron no difundir $D e$ iure praedeae íntegramente, y ello se explica porque cuando este trabajo lo terminó de escribir Grocio, entre 1604 y 1608, algunos plenipotenciarios de Holanda y de la Monarquía Hispánica (Portugal y sus colonias también formaron parte de ella entre 1581 y 1640) tenían ya en mente suspender temporalmente sus viejas hostilidades y asperezas, lo que finalmente se hizo en la ciudad de Amberes el 9 de abril de 1609, y por un periodo de más de una década, hasta $1621 .^{5}$ Sin embargo, en la recién fundada editorial Elsevier, de Leiden, se decidió publicar, aunque es cierto que de forma anónima, un capítulo princi-

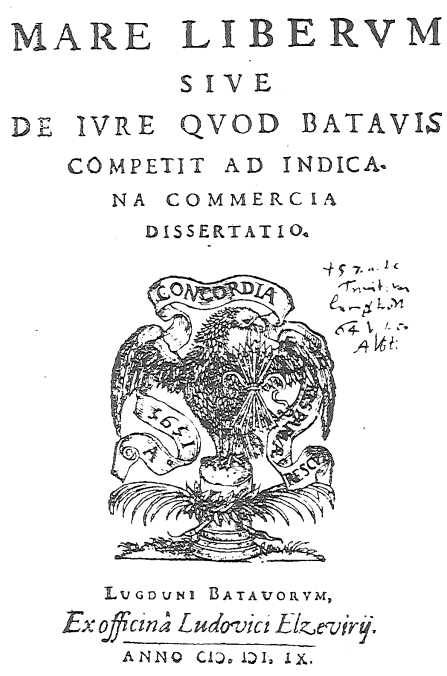

Portada de Mare liberum, de Hugo Grocio (1609). pal del texto mencionado - el XII-, cuyo título completo era Mare liberum sive de iure quod batavis competit ad indicana commercia, dissertatio (1609). ${ }^{6}$ Este libro (uno de los escritos fundamentales de la ciencia jurídica internacional, no solo por su propio contenido doctrinal sino por su trascendencia teórica y práctica) cuestionaba el monopolio mercantil obtenido por los portugueses (e indirectamente también el de los españoles, a los que estaban dinásticamente unidos desde el reinado de Felipe II) en las Indias orientales entre finales del siglo XV y principios del XVI gracias al apoyo de la curia papal. Su publicación motivaría la respuesta tardía pero notable del portugués Serafín de Freitas (1570?-1633) con su De iusto imperio lusitanorum asiatico (1625). ${ }^{7}$

5 Ittersum, 2009a. García, 2009.

6 Hasta que se editó la segunda edición, en 1618, no apareció el nombre de Hugo Grocio. Por ejemplo, William Welwood (1613) indicaba que Mare liberum (1609) estaba escrito por un autor «desconocido». Serafín de Freitas (1625) califica también al autor de Mare liberum de «desconocido» e «incógnito», lo mismo que Juan de Solórzano (1629).

7 Merea, 1924. Miaja, 1932-1933. Caetano, 1983. Alexandrowicz, 1998. Pagden, 2000. Brito, 2003. 
Basta apenas con hojear las páginas de la mencionada obra de Hugo Grocio para apreciar que su postura contraía evidentes deudas con el pensamiento de la segunda escolástica hispana contenido en textos seminales como De Indis et Iure Belli relectiones (1532) de Francisco Vitoria (1483/1486-1546), In regulae Peccatum, de regulis Iuris lib. VI (1554) de Diego de Covarrubias y Leiva (1512-1577), y Controversiarum illustrium aliarumque usu frequentium libri tres (1564) de Fernando Vázquez de Menchaca (1512-1569). ${ }^{8}$ El pasivo con estos tres autores — sobre todo con el primero y el último - es notable, pues en De iure praedae se han podido contabilizar 68 referencias a Vitoria y 74 a Menchaca. ${ }^{9}$ Es más, Grocio, como los citados Vitoria y Menchaca, compartía admiración por el viejo concepto de libertad que formulase Ulpiano: «mare commune omnium est sicut aer». Es decir, «el mar pertenece a todo el mundo como el aire».

El principal propósito de este artículo consiste en comprender y entender, en su propio contexto, ${ }^{10}$ esta disputa político-intelectual o «gran batalla libresca» (la expresión la hizo célebre hace algo más de cien años el experto en derecho internacional Ernest Nys) en torno al principio de la libertad o del dominio marítimo iniciada en Holanda a principios del siglo XVII y sostenida con cierta viveza y pasión en toda Europa durante la centuria restante y parte de la siguiente. ${ }^{11}$ La confrontación de los mencionados trabajos de Hugo Grocio y Serafín de Freitas resulta por tanto ineludible. Unos datos biográficos sobre ambos autores y sobre el particular y convulso marco histórico en el que se encuadran sus respectivas obras nos permitirán entenderlas mejor.

\section{Serafín de Freitas y Hugo Grocio: vidas distintas pero cruzadas}

Al contrario de lo que se suele admitir, el jurisconsulto inglés John Selden (1584-1654), con su Mare clausum (1635), no fue el primer autor ni el único que cuestionó el derecho al libre tránsito y comercio por los mares y océanos del mundo que defendiera el «anónimo» autor de Mare liberum

8 Pagden, 1988. Brett, 1997. Gelderen, 1999.

9 Brito, 2003, 362. Gómez Rivas, 2013.

10 Véanse las todavía originales observaciones de teoría y método formuladas por Skinner, 1969. Asimismo, resulta obligada la lectura de la compilación de ensayos de Pocock, 2011.

11 Nys, 1901, 260-267 (la expresión en la página 260). Schmitt, 1979, 174-219. Haakonssen, 1996. Schneewind, 1998. Pagden, 1997 y 2002. Lesaffer, 2009 (agradezco la referencia a Pablo Fernández Albaladejo). Armitage, 2013, 46-56. 
(1609). Una sistemática y notable crítica - no siempre puesta de manifiesto por la historiografía- al trabajo de Grocio, si prescindimos de Minos seu mare tutum (texto incompleto e inédito redactado por el jesuita flamenco Nicolás Bonaert en 1610), y del ya citado An abridgement of all the sea laws (1613), del escocés William Welwood (1566-1624), fue realizada por el portugués Serafín de Freitas en De iusto imperio lusitanorum asiatico (1625). ${ }^{12}$ Religioso perteneciente a la Orden de la Merced y profesor de derecho canónico en la Universidad de Valladolid, Freitas publicó este libro, dedicado a Felipe IV, cuando apenas le quedaban ocho años de vida, cuando Portugal y sus posesiones de Ultramar hacía casi medio siglo que estaban siendo gober-

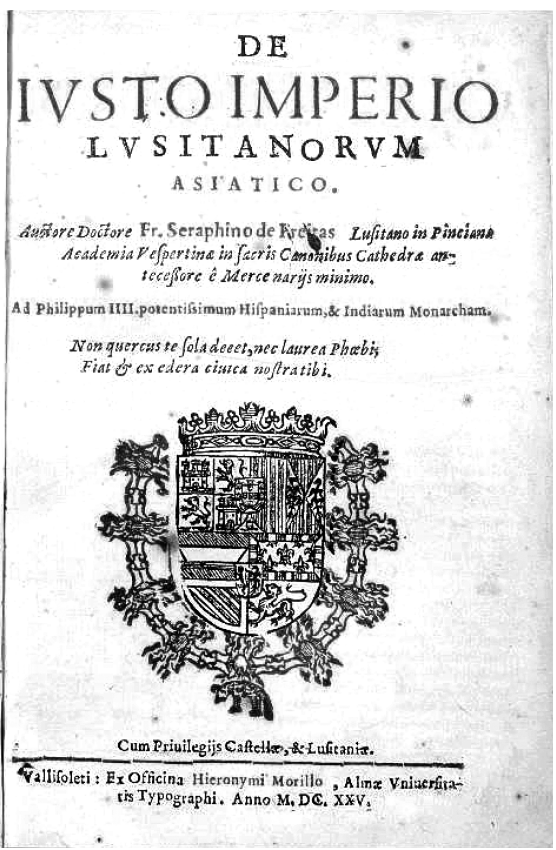

Frontispicio de De iusto imperio lusitanorum asiático, de Serafín de Freitas (1625). nadas por los Habsburgo españoles debido a la extinción natural de la dinastía Avís, y cuando dicha agregación territorial estaba siendo más cuestionada que nunca, tanto dentro de la península ibérica como fuera de ella. ${ }^{13}$

Ante la imposibilidad de hallar documentos sobre el nacimiento de Serafín de Freitas (la parroquia en la que fue bautizado sufrió graves e irreparables daños tras el terremoto de Lisboa de 1755), todavía resultan válidos los datos biográficos sobre sus orígenes proporcionados hace algún tiempo

12 Nussbaum, 1949, 359-463 (este trabajo incluye unas «adiciones sobre Historia de la doctrina hispánica de Derecho Internacional» a cargo de Luis García Arias). Schmitt, 1979, 96-153. Mariño, 1992. Ittersum, 2008.

13 La bibliografía sobre la agregación de la Corona de Portugal a la Monarquía Hispánica ya es prolija. Algunos de los mejores trabajos son los de Valladares, 1998 y 2008; Schaub, 2001; Bouza, 2005; y Cardim, 2014. La importante dimensión colonial de la Unión de Coronas, menos atendida por algunos de los investigadores citados, se aborda en Subrahmanyam, 1999; Veen, 2000; Valladares, 2001; Gruzinski, 2004; Ramada Curto, 2009; Martínez Shaw y Martínez Torres, 2014; Elliott, 2015 (agradezco al autor que me facilitara copia de este importante trabajo); Martínez Torres, 2016. 
por algunos autores que se acercaron a su obra, juristas portugueses y españoles especializados en derecho internacional y religiosos pertenecientes a su Orden fundamentalmente. ${ }^{14}$ Según recogen estos trabajos, Freitas nació en Lisboa alrededor de 1570, en un barrio cercano a la concurrida plaza del Comercio. Hijo de un hidalgo portugués llamado Antonio de Freitas (de su madre no tenemos ninguna noticia), estudió gramática y humanidades con los jesuitas del colegio de San Antonio, trasladándose a Coimbra en 1588 para estudiar derecho canónico. En la Universidad de Coimbra recibió los grados de bachiller, licenciado y doctor; título este último que alcanzó en 1598, apenas muerto Felipe II en su palacio de El Escorial. Nada más doctorarse decidió optar a una cátedra de derecho canónico que había vacante en Coimbra. No la consiguió, y por tanto tuvo que aspirar a la que ofrecía la Universidad de Valladolid, donde ejerció de catedrático de vísperas y cánones hasta 1608. Precisamente en estas fechas decide ingresar en la mencionada Orden de los mercedarios.

En Valladolid, capital política de la Monarquía Hispánica durante algo más de un lustro (entre 1601 y 1606) y residencia de algunas de sus principales casas nobiliarias, fue respetado su buen hacer jurídico, dejando escritas un total de 19 «alegaciones» en materia de derecho canónico. ${ }^{15} \mathrm{Se}$ gún parece también, y pese a que es cierto que Freitas nunca disfrazó sus simpatías hacia las ideas independentistas que representaban sus amigos el arzobispo de Lisboa don Rodrigo de Cunha y Silva (1577-1643) y el entonces VIII duque de Bragança, don João (rey de Portugal entre 1640 y 1645), Felipe IV quiso concederle un destacado obispado para atraerlo a su causa, cargo que finalmente no aceptó alegando no encontrarse bien de salud. Aquejado de una fuerte sordera y de achaques propios de la vejez, decidió abandonar la docencia universitaria en la década de los veinte, muriendo en Valladolid el 11 de junio de 1633.

Si comparamos la poco conocida biografía de Serafín de Freitas con la divulgada de Hugo Grocio, ${ }^{16}$ su antagonista en materia doctrinal, comprobaremos que mientras que Freitas escribía en su madurez y como fruto del aprendizaje y práctica de la regulación jurídica de la Iglesia católica,

14 Miaja, 1932-1933, 174-176. Bensabat Amzalak, 1935. Barcia Trelles, 1946. El más completo estudio biográfico sobre Serafín de Freitas es el que proporciona Placer López, 1956, que incluye un apéndice final con toda su obra doctrinal y poética.

15 Placer López, 1956, 93 y ss.

16 Los libros sobre la vida y obra de Hugo Grocio son abundantes (véase asimismo: Edwards, 1981. Kahn, 1983). Un clásico e informativo trabajo es el de Levesque de Burigny, 1752. El mejor y más completo trabajo es el de Ittersum, 2006, que he seguido en todo este punto. 
Hugo Grocio, nacido en Delft el 17 de abril de 1583, ya lo hacía más que solventemente en su infancia. Con tan solo 11 años comenzó sus estudios de leyes en la Universidad de Leiden, ejerciendo de letrado en La Haya en 1599, y ya como fiscal general de toda Holanda en 1607. Igual que Michel de Montaigne (1533-1592) o Tycho Brahe (1546-1601), Grocio también fue un niño prodigio, pues además de conocer profundamente el derecho romano, tenía vastos conocimientos de matemáticas, teología, astrología, historia y poética. A finales del siglo XVI, nada más acabar derecho en Leiden, Grocio entra de lleno en la vida pública de su patria, formando parte de una misión diplomática encabezada por el estatúder Justino de Nassau (1559?-1631) y el consejero político Johan van Oldenbarnevelt (1547-1619), cuyo fin era confirmar una alianza holandesa con Enrique IV de Francia (1589-1610). ${ }^{17}$ Tal maniobra finalmente no se llevó a cabo, pero le sirvió a Grocio para alcanzar en 1613 la dignidad de procurador de la ciudad de Rotterdam. Caído en desgracia en 1619 por sus fuertes convicciones liberales (se oponía tanto a la ortodoxia calvinista como a la de la Casa de Orange), fue condenado a cadena perpetua y a la confiscación de todos sus bienes materiales. En prisión permaneció dos años, lo que le sirvió para leer y escribir con verdadera voracidad e incontinencia. En 1621, con la ayuda de su mujer, María van Reigersberg, se fugó pintorescamente (escondido en un gran cofre que solía contener ropa sucia y libros) de la cárcel para instalarse en Francia, donde fue protegido del rey Luis XIII hasta 1631. Ese mismo año decidió regresar a Holanda, pero tuvo que huir un año después a Hamburgo y Estocolmo. En la corte de la reina Cristina de Suecia, donde también encontró acomodo el matemático y filósofo René Descartes (1596-1650), se le reconoció su extraordinaria valía como jurista y diplomático y se le nombró, en 1635, embajador ante Francia, cargo que ocupó hasta 1645, cuando inesperadamente falleció en Rostock de regreso de una misión diplomática. Grocio fue para Holanda lo que más tarde John Locke (1632-1704) sería para Inglaterra, el más influyente pensador y polemista de su tiempo. Aunque se consideraba teólogo, filósofo, historiador y poeta (por este orden), su implicación en cuestiones legales estaba marcada no solamente por la tradición europea del estudio del derecho romano, sino también por los debates humanistas sobre filosofía moral y política. ${ }^{18}$

17 Mann, 1988, 162-163.

18 Gelderen, 2009, 197. 


\section{La rivalidad ibero-holandesa en la Indias orientales}

Durante buena parte del tiempo en que escribieron y publicaron Grocio y Freitas sus mencionadas y opuestas obras, entre 1604 y 1625 respectivamente, los holandeses y los ibéricos fueron enemigos declarados. Obviamente la rivalidad que mantuvieron por el control político y mercantil de las Indias orientales también fomentó esta disputa intelectual, cuya raíz se encuentra en la larga y sangrante guerra por la independencia de la Monarquía Hispánica que mantenían las 17 provincias de los Países Bajos desde hacía algo más de tres décadas. Desde 1595 (salida del puerto de Amsterdam de las primeras flotas mercantiles con rumbo a las islas Molucas) hasta 1640 (separación de Portugal de España), los choques entre los holandeses y los ibéricos fueron recurrentes en las posesiones hispano-portuguesas de Asia, codiciadas por la riqueza de sus principales materias primas (pimienta, nuez moscada, clavo y sándalo fundamentalmente).${ }^{19}$ Pero no todo fue guerra. Hubo momentos de declarado alto el fuego como la aludida Paz de Amberes (1609-1621), que resultó ser un fracaso para la Monarquía Hispánica, pues sirvió para que los holandeses rearmaran su ya de por sí poderosa flota naval (desde 1571 disponían de unas 232.000 toneladas frente a las 300.000 que poseían en conjunto España y Portugal) gracias a las ganancias obtenidas con un tráfico de contrabando realizado no pocas veces con la connivencia escandalosa de autoridades españolas y portuguesas. ${ }^{20}$

Hay que indicar, asimismo, que este armisticio no resultó ser ningún impedimento para que los marinos holandeses siguieran con sus tratos mercantiles en las Indias orientales. Al contrario, los intercambios fueron en aumento gracias a una hábil política de pactos y alianzas con las autoridades autóctonas de los principales lugares de donde los bátavos extraían la canela (Ceilán), la pimienta (Java y Sumatra), la nuez moscada, el sándalo (Banda) y el clavo (Amboina). La dificultad de defender los intereses de la Monarquía Hispánica en tan lejanos y dispersos territorios planteó incluso la posibilidad de «trocar» las levantiscas y costosas Provincias Unidas por los lucrativos territorios de las Indias orientales. Felipe III de España (II de Portugal) no solo sería el «rey de la plata», sino un verdadero monarca «especiero» con «señorío y dominio de toda 2013.

19 Boxer, 1982. Subrahmanyam, 1999, 185-228. Veen, 2000, 75-81 y 147-171. Crespo Solana,

20 Usher, 1928. Alloza, 2014. 


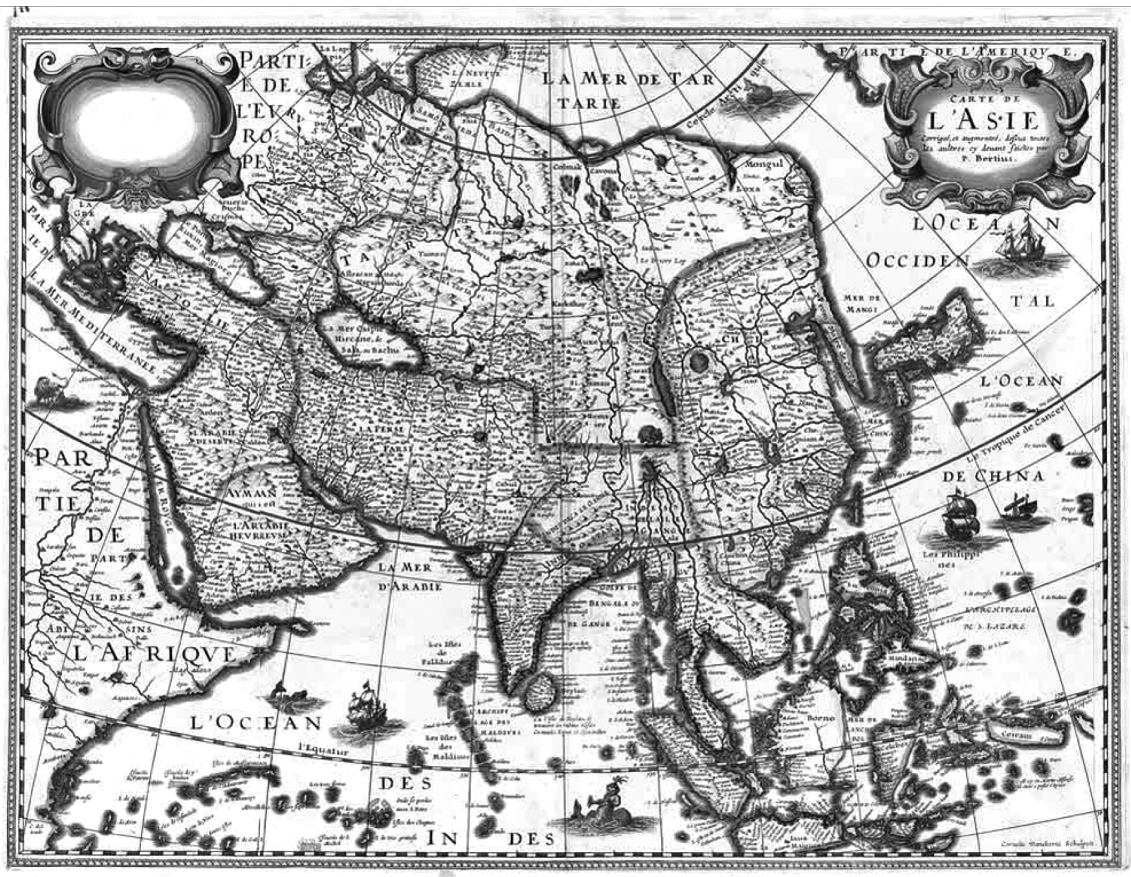

Mapa de Asia (1627). Petrus Bertius.

la Mar del Sur», lo que no habían conseguido nunca el emperador Carlos V ni Felipe II. ${ }^{21}$

Esta difícil convivencia entre los marinos holandeses y los vasallos de la Monarquía Hispánica en el sudeste asiático se fue agravando aun más si cabe con la fundación, en 1602, de la mencionada VOC y, en 1621, con el nacimiento de la Compañía de las Indias Occidentales (West Indische Compagnie, o WIC). El área de competencia de Holanda con la Monarquía

21 Archivo General de Indias (AGI), Indiferente General, 1.868. La expresión «rey de la plata» la ha hecho célebre Carlo M. Cipolla en La odisea de la plata española. Conquistadores, piratas y mercaderes (Barcelona, Crítica, 1999). Asimismo, la alusión a Felipe III como «rey especiero» procede de los memoriales de Pedro de Baeza, mercader madrileño con más de 25 años de experiencia en el Oriente ibérico. Véase Biblioteca Nacional de España: R/14.034 (1608-1609). Referencias recurrentes al «señorío y dominio de la Mar del Sur» en Sherley, 2010 [1622]. Sobre Pedro de Baeza y otros célebres memorialistas del Asia ibérica (Hernando de los Ríos Coronel, Duarte Gomes Solís, Juan Grau Monfalcón...) durante la unión de Portugal a la Monarquía Hispánica preparo actualmente un detallado artículo, así como una edición de algunos de sus principales textos para el Centro de História d'Aquém e d'Além-Mar (Lisboa). Posiblemente su publicación verá la luz en 2017. 
Hispánica para contrarrestar su monopolio mercantil abarcaba así el suroeste de la India, las islas Molucas, Macao, Filipinas, el Brasil, la desembocadura del Río de la Plata y el continente africano en todo su perímetro. ${ }^{22}$ El ataque a las fortificaciones ibéricas de Ultramar y el asalto a sus navíos, cargados de ricas, necesarias y exóticas mercancías, fue una imagen cotidiana en el primer tercio del XVII. La literatura y la pintura dan buena fe de ello. Estos enfrentamientos fueron lo más parecido a una guerra «mundial» o «global», probablemente la primera en la historia. En 1606 y 1623, por ejemplo, los productos que acostumbraban a traer a Europa los galeones portugueses de la Carreira da Índia no llegaron a descargarse en Lisboa debido a que su puerto y el de Goa, vinculados desde que llegaran a estas latitudes Vasco de Gama (1460-1529), Fernando de Magallanes (1480-1521) y Juan Sebastián Elcano (1476-1526), se encontraban cercados por navíos neerlandeses de gran tonelaje y extraordinaria potencia artillera. De todo el periodo que la Corona de Portugal y sus colonias permanecieron unidas a la Monarquía Hispánica, el arco cronológico comprendido entre 1629 y 1636 resultó ser extraordinariamente convulso para los lusos que estaban asentados en las poblaciones del océano Índico, sobre todo en las aguas del estrecho de Malaca y en la costa Malabar, pues cerca de 150 de sus barcos (algo más de la mitad de la flota mercante que tenía en estos momentos) fueron asaltados y destruidos por los marinos bátavos. ${ }^{23}$

La peligrosidad que aquí estamos mencionando tuvo su reflejo en el descenso del tráfico comercial luso-indio, extraordinariamente patente entre 1630 y 1640 , y no a partir de 1590 como se tenía admitido. ${ }^{24}$ Para una serie de recientes investigaciones no existen dudas: la decadencia de la $\mathrm{Ca}$ rreira da Índia comienza en 1636, momento en el que la VOC empieza a realizar una serie de calculados bloqueos marítimos contra Goa, la «llave de toda la India» en célebre expresión de la época. ${ }^{25}$ Evidentemente que no hay que subestimar los perniciosos efectos que tuvo el corso holandés en el declive de la Carreira, pero lo cierto es que entre 1595 y 1625 (primeros avistamientos de naves holandesas en el Estado da Índia y publicación de las obras de Hugo Grocio y Serafín de Freitas) las pérdidas de naves portuguesas por la impericia de los pilotos y por el imponderable climático fueron más, en términos absolutos y relativos, que las producidas por los

22 Boxer, 2001. Israel, 1996. Emmer, 2003.

23 Boxer, 2002, 287.

24 Disney, 1981, 153-189. Godinho, 1990.

25 Murteira, 2012 (95-212) y 2014. 
corsarios holandeses. Sin embargo, uno de los asaltos corsarios que más trascendencia tuvieron en estas fechas fue, desde la óptica que imprime la historia político-intelectual europea, y como ha quedado subrayado al principio de este trabajo, la captura holandesa en 1603 de la nave portuguesa Santa Catarina, legitimada unos pocos años después por Hugo Grocio en Mare liberum.

\section{Mare Liberum versus Mare Clausum}

No resulta difícil imaginar la conmoción que, a principios del siglo XVII, pudo llegar a ocasionar la publicación del Mare liberum de Grocio entre las autoridades de España y Portugal, unidas durante algo más de medio siglo, y con asentamientos y factorías mercantiles en las «cuatro partes del mundo» conocido en esos momentos. El impacto del pensador holandés en la península ibérica resultó considerable. En cierto modo lo demuestra el hecho de que tan solo tres años después de su salida de la imprenta, en 1612, Mare liberum fuera incluido en el Index librorum prohibitorum et derogatorum de la Inquisición española. En Portugal habrá que esperar un poco más, hasta 1624, para que el conjunto de la producción grociana publicada hasta esa fecha (un total de 14 obras entre textos históricos, de derecho y piezas de teatro fundamentalmente) sea anatemizada por la parte más reaccionaria y combativa de la Iglesia católica. ${ }^{26}$ ¿Qué explica esta animadversión de las principales autoridades del sur de Europa por el autor de Mare liberum? Obviamente su cuestionamiento al «legítimo» reparto y explotación del mundo que, con el apoyo de la cancillería papal, habían realizado los soberanos de España y Portugal amparándose en los célebres y controvertidos tratados de Alcaçovas (1479), Tordesillas (1494) y Zaragoza (1529). Para Grocio no había dudas posibles: «una cosa era poseer algo y otra muy distinta era tener derecho para poseerla». ¿Es lícito - se preguntaba el jurista de Delft- entregar a dos pueblos casi los dos tercios del mundo? Este sin duda era el nudo que Hugo Grocio estaba dispuesto a desatar con sólidos argumentos, distintos sin duda a los manejados por Serafín de Freitas en De iusto imperio lusitanorum asiatico, uno de su principales rivales en materia doctrinal como ahora sabemos. ${ }^{27}$

26 Baiāo, 1919. Pinto Crespo, 1983. Pardo Tomás, 1991. Bethencourt, 1997.

27 Grocio, 1979, [1609], 57-58 y ss. 
Comenzando por el principio, por la estricta declaración de intenciones de Mare liberum, Grocio negaba con rotundidad y vehemencia cualquier tipo de derecho de Portugal y España en las Indias orientales conferido en base a los supuestos de «descubrimiento» (capítulos V y IX), «concesión papal» (capítulo VI) y «prescripción» (capítulos VII y XI). Su disertatio demostraba, según el ius gentium y el ius communicationis formulado por Francisco de Vitoria, que cualquier pueblo, no solo el holandés, podía navegar y comerciar libremente en aguas asiáticas. Nadie, ningún príncipe de la cristiandad —incluido el sumo pontífice-, podía prohibir el legítimo acceso de los mercaderes neerlandeses a las Indias orientales, objetivo preferencial de sus intereses económicos. Tal declaración de principios, fundamentada en el citado derecho de gentes y en el de comunicación, partía además de una inmutable razón: «todas las gentes pueden relacionarse y negociar entre sí». ${ }^{28}$ Actualmente estos supuestos histórico-legales son ampliamente admitidos, pero en el pasado no estaba tan claro. El mismo Grocio constituye un ejemplo. Si a principios del siglo XVII defendía para Holanda y otras repúblicas y monarquías el derecho a navegar y comerciar libremente en los mares y océanos donde tradicionalmente venían haciéndolo los ibéricos, poco antes de morir en 1645 redactó informes en los que solicitaba para Suecia el monopolio mercantil en el Mar del Norte.

Serafín de Freitas, desconociendo la identidad del autor que pretende refutar pero no su nacionalidad (repetitivamente Grocio es llamado el «desconocido», el «incógnito»), desde el inicio de su De iusto imperio lusitanorum asiatico señala también las razones de fondo que le han llevado a escribir su trabajo. Sus palabras, como su estilo, son menos precisas que las de Hugo Grocio. Sin embargo, también merecen destacarse por su contundencia:

Los holandeses, que ya se habían sustraído a la fidelidad y obediencia debidas a su propio y natural Señor, so pretexto de su rebelión, comenzaron a perturbar con hechos el derecho correspondiente a los portugueses en los emporios de Indias y su imperio; y al ser rechazados repetidas veces por los nuestros, un desconocido apela de las armas al derecho en nombre de sus coterráneos (sic), y en un libro, al cual puso por nombre Mare liberum, ejercita su ingenio llamando a los españoles partidores y usurpadores del océano, si bien dirige sus tiros principalmente a menoscabar y destruir el derecho de Portugal de navegar con rumbo al Asia y comerciar con sus indígenas. Frecuentemente se las echa de vencedor, aunque conculca sin miramientos todos los fundamentos del derecho, que a su antojo muda y trastueca sin dejar verde ni seco, y

28 Ibidem, 62-68. 
en lo único que le hallo digno de alabanza es en no haber osado revelar su nombre, temiendo acaso que al ser tomado en tan torcidas interpretaciones y tantas imposturas, lejos de merecer premio y gloria habría de sufrir vituperios. ${ }^{29}$

Prácticamente todo el contenido de la obra de Serafín de Freitas se corresponde exactamente con el ya citado Mare liberum de Hugo Grocio. Las 18 partes que componen De iusto imperio lusitanorum asiatico ${ }^{30}$ siguen casi al pie de la letra los 13 apartados en que divide Hugo Grocio su trabajo. No obstante, su refutación la hace de acuerdo a dos peculiares características:

a) Método analítico extensivo. Freitas en ningún momento considera en su conjunto la tesis de Hugo Grocio favorable a la libertad de navegar y comerciar en los mares y océanos de las Indias orientales, sino que su método de análisis consiste en examinar uno a uno todos los argumentos y citas de los que se sirve Grocio para sostener su tesis. La utilización de este método dota a su obra de una gran extensión (casi cuatro veces más amplia que Mare liberum) y complejidad.

b) Utilización de toda clase de fuentes, pero preferencia por las de derecho canónico. Esto era algo natural entre los jurisconsultos de la época. ${ }^{31}$ Grocio hace lo mismo que Freitas en Mare liberum, y todavía con mucho más en detalle en De iura praedae, que como sabemos era el texto matriz. Sin embargo, Freitas, probablemente por su formación canonista, hace un uso desproporcionado del derecho canónico en De iusto imperio lusitanorum asiatico, lo que explica las largas y farragosas digresiones (él mismo reconoce que pueden ser «pesadas» para un lector no especializado) para rebatir las interpretaciones dadas a algunas leyes por Grocio, que según el mercedario portugués «juzga de manera equivocada». Sus palabras preliminares ilustran magníficamente este último aspecto:

Enseña nuestro Incógnito que puede promover la acción de injurias aquel a quien se vedare pescar en el mar, o delante de mi casa; invocando para ello el si quis me de injuriis en la Ley de injuriis, que contiene un dicho de Ulpiano, pero bonitamente se calla lo que el mismo Ulpiano enseña a propósito del arrendador público, respecto del cual establece regla contraria. Enseñó el jurisconsulto Paulo en la Ley sane contenida en el título De injuriis, que a quien tiene propio derecho sobre el mar compete el interdicto uti possidetis, si se viese perturbado en su ejercicio; pero nuestro autor trocó la

29 Freitas, 1925 [1625], 19.

30 Los capítulos XV, XVI, XVII y XVIII dejan un poco de lado la polémica con Grocio y se intitulan: «De la fidelidad y verdad de los portugueses», «De las riquezas de los portugueses antes de que navegaran a Indias», «Del lucro que reporta a los portugueses el comercio índico» y «De la religión de los portugueses en la India oriental», respectivamente.

31 Tomás y Valiente, 1986. Clavero, 1994. Grossi, 1996. Hespanha, 2002. 


\section{JOSÉ ANTONIO MARTÍNEZ TORRES}

palabra maris por el vocablo divertículo, y así esquivó la dificultad. Por añadidura solo admite los Doctores, cuyos dichos, a lo menos como él los interpreta, le favorecen, y tacha a los demás de aduladores, y con estas y otras semejantes ventajas provoca confiadamente a juicio. ${ }^{32}$

No tenemos constancia de que Hugo Grocio respondiera a estas acusaciones de manipulación por parte de Serafín de Freitas, pues por esas fechas se encontraba exiliado en Francia y ocupado en intereses diferentes. ${ }^{33}$ Todo lo cual no significa que no conociera la obra del publicista y religioso portugués. Así, en la informativa correspondencia que mantuvo con su hermano, Grocio constata, con errores de fecha y lugar probablemente, la existencia, en abril de 1617, de una refutación a su Mare liberum escrita en Salamanca. Es más, en otra carta de febrero de 1627 Grocio anotaba haber leído una obra llamada De iusto imperio lusitanorum asiático. ${ }^{34}$

Ya se ha dicho que el objetivo de Freitas era rebatir los argumentos de Grocio sobre el hecho de que los mares y océanos que había en el continente asiático no podían ser objeto de propiedad del rey de España y Portugal por derecho de «descubrimiento», «concesión papal»y «prescripción». La propia naturaleza del agua se resistía a esto. Parafraseando las palabras de Freitas, el océano «era tan ilimitado» que nadie podía poseerlo. ${ }^{35}$ Esta imposibilidad natural también se extendía a la tierra, y más en concreto a todo el conjunto de posesiones portuguesas «descubiertas» en Ultramar desde los tiempos del infante Enrique (1394-1460) y el rey Manuel I (1495-1521). Todas ellas contenían inmensos desiertos, montañas, bosques, ríos, arroyos y lagos que no podían ser divididos por ningún hombre, ni siquiera por el papa. Ahora bien, a la tesis grociana del derecho a beber agua por ser necesario a la supervivencia humana como el aire que se respira, Freitas replicaba que no era lo mismo que «el derecho a pescar o comerciar». ${ }^{36}$ Los holandeses podían beber todo el agua del océano Índico y los mares adyacentes si querían hasta terminar por hartarse, pero lo que no podían hacer era comerciar y sacar provecho de «los trabajos, los sacrificios, la sangre y la vida de otros». ${ }^{37}$ Esta «oportunista» capacidad de los holandeses de meterse entre los resquicios del imperio de los ibéricos, pero sobre todo su «deslealtad»

32 Freitas, 1925 [1625], 8.

33 Véase supra.

34 Grocio, 1687, Epístola nº 144, 796. Levesque de Burigny, 1754, t. 1, 64.

35 Freitas, 1925 [1625], 150 y ss.

36 Grocio, 1979 [1609], 84-115. Freitas, 1925 [1625], 150-324.

37 Freitas, 1925 [1625], 342-363. 
para con su legítimo y «propio rey», era lo que más molestaba a Freitas del autor de Mare liberum. «No se ha de tomar venganza contra los padres ni contra la Patria, a quienes, después de Dios, debemos la vida, la índole y la educación», señalaba el mercedario portugués. Y tanto menos —insistía en este punto- contra el régimen de los reyes de España, que «tiene más de paternal que de señorial, como es notorio hasta a los extranjeros»..$^{38}$

Pese a las críticas de «oportunismo» $\mathrm{y}$ «deslealtad» para con aquellos holandeses que habían decidido desplazarse hasta las poblaciones de las Indias orientales con el fin de efectuar sus «pérfidas» negociaciones mercantiles, Serafín de Freitas aceptaba, al igual que Hugo Grocio, que tanto el derecho de navegar como el de comerciar que les amparaban fueran parte del derecho de gentes, pero no los consideraba derechos primarios, ilimitables. ${ }^{39}$ Según Freitas, navegar y comerciar eran derechos propios de la «naturaleza caída», que no existían en el «estado natural», y por eso mismo podían ser regulados por el derecho positivo o la ley escrita que tenía cada república o monarquía en particular. ${ }^{40}$ La complejidad de su pensamiento en este apartado en concreto es harto considerable, pues en otras secciones de su obra habla de la existencia de una «dualidad» que es fruto de dos estados de naturaleza humana, el de «naturaleza íntegra» y el de «naturaleza corrupta». El comercio obviamente pertenecía a esa segunda naturaleza - la corrupta- y los holandeses («una raza dañina» en opinión de Serafín de Freitas), con el uso de tales prácticas y abusos parecía que habían «nacido para saquear a otras naciones». ${ }^{41}$ Había muchos ejemplos de las «malas artes» realizadas en los tratos por los mercaderes holandeses, pero era ilustrativo el que proporcionaba la Historia de Etiopía Oriental. Según glosaba Freitas, dos naves holandesas que habían llegado a Java en 1600 para aprovisionarse de mercancías (nuez moscada probablemente) pagaron sus intercambios con monedas de cobre «artificiosamente plateadas». Descubierto el engaño, los responsables pagaron con el castigo y la cárcel, $\mathrm{y}$ «a duras penas pudieron lograr de los javaneses que esperasen a que llegara otra expedición de holandeses, quienes les pagarían en buena moneda a su satisfacción». ${ }^{42}$

38 Ibidem, 328-329.

39 A diferencia de Grocio, Vitoria y Menchaca, Freitas no era partidario de dividir el «derecho de gentes» en dos: el «derecho de gentes primario», aplicación de la ley natural a las relaciones internacionales, y el «derecho de gentes secundario», nacido de los usos y las costumbres. Sobre todo ello informan en detalle: Carro, 1944. Carpintero, 1977.

40 Freitas, 1925 [1625], 22, 295, 297.

41 Ibidem, 330.

42 Ibidem, 329-330. 
Hugo Grocio, que profesaba una religión distinta a la de Serafín de Freitas, lógicamente no le otorgaba ninguna validez a la donación papal de la Indias orientales a los reyes de Portugal y España. ${ }^{43}$ Para Grocio «nadie es dueño de lo que ni él ni otro en su nombre poseyó». Los territorios asiáticos que, según argüían los publicistas y cronistas portugueses, eran suyos por «descubrimiento» $\mathrm{y}$ «ocupación», tenían y «siempre tuvieron sus reyes, su estado, sus leyes y sus derechos». El comercio era una «concesión» de sus autoridades para con los mercaderes lusos como lo probaba el hecho de «que pagan tributos y pedían [a sus príncipes asiáticos] el derecho de comerciar». ${ }^{44}$ Todo lo cual atestiguaba que los portugueses venían como «extranjeros» y no habitaban en esas tierras sino por permiso. Esta ausencia de derecho de dominio por título de descubrimiento también la corroboraba el Digesto $(41,2,3)$, que solo otorgaba «derechos sobre aquellas cosas que antes del descubrimiento eran res nullius». ${ }^{45} \mathrm{Y}$ este precisamente no era el caso de los pueblos que había antes de que llegaran los marinos y soldados lusos a las Indias orientales. Indudablemente, sentenciaba Grocio, todos eran «idólatras envueltos en graves pecados», pero tenían «dominio público y privado de sus cosas y territorios, lo cual sin justa causa no se les podía quitar». Santo Tomás de Aquino (1224 o 1225-1274), Francisco de Vitoria y Fernando Vázquez de Menchaca ya lo habían dicho antes mucho mejor: «no pueden los cristianos seglares ni los eclesiásticos privar a los infieles del poder civil y de la soberanía solamente porque son infieles». El quitarles las propiedades que poseían, recalcaba Grocio, era un robo no menor que si se hiciese entre cristianos. ${ }^{46}$

La propiedad de los mares de las Indias orientales que Freitas reclamaba para Felipe IV de España (III de Portugal), aludiendo al derecho de «descubrimiento», a la ocupación y a «los trabajos, los sacrificios, la sangre y la vida» dada por tantos portugueses y españoles, en cierto modo se supeditada a una interesante interpretación - y esto quizás sea lo más novedoso de su trabajo - de las bulas papales de donación del mundo, que en cierta medida le distancia de las posturas defendidas unos años antes por relevantes colegas suyos como los mencionados Vitoria y Menchaca. El papado, según opinaba Freitas, no podía conceder a los portugueses ni a los españoles ni a otras «naciones católicas» el derecho «de navegar y viajar a

43 Grocio, 1979 [1609], 69-77.

44 Ibidem, 69.

45 Ibidem, 71.

46 Ibidem, 72. 
las Indias» de manera metapositiva, in abstracto ${ }^{47}$ En cambio la Iglesia, la reunión de todos los fieles en el sentido etimológico del término, sí tenía, y el papa en particular, como vicario de Dios en la tierra, la auctoritas suficiente para otorgar a un monarca el derecho exclusivo de evangelizar, lo que indirectamente conllevaba la misión de comerciar y conquistar sin límites ningunos. Nicolás V (1447-1455), Calixto III (1455-1458) y Alejandro VI (1492-1503) lo habían corroborado así en sus oportunas bulas, pues «jamás concedieron a secas y por sí solos a los portugueses [y a los españoles] los derechos de navegar y comerciar con los indios, sino que lo hicieron por vía de corolario y compensación del derecho más importante y capital de enviar predicadores y convertir infieles». ${ }^{48} \mathrm{La}$ fórmula que se repetía desde mediados del siglo XV en todas la bulas y cédulas emitidas desde Roma así lo atestiguaba: los soberanos católicos «prestarían un singular obsequio a Dios si con su trabajo e industria lograban hacer navegable el mar que conduce hasta los Indios». ${ }^{49}$ Pese al agotamiento sufrido por la autoridad papal desde mediados del siglo XVI, portugueses y españoles obtenían así un vínculo histórico con el imperio como segunda espada de la cristiandad que pocos soberanos de Europa, hasta bien avanzado el siglo XVIII se atrevieron a disociar. ${ }^{50}$

El derecho de prescripción era el tercer y último punto que Hugo Grocio estaba dispuesto a cuestionar al soberano de España y Portugal para acabar definitivamente con su «legítimo» monopolio mercantil en las Indias orientales. La prescripción, señalaba Grocio, era propia del derecho civil, por lo cual no tenía ningún tipo de cabida entre reyes o pueblos libres como Holanda. ${ }^{51} \mathrm{Y}$ menos aun donde el derecho civil y el de gentes convivían, pues siempre prevalecía el segundo frente al primero. El ya mencionado Digesto lo había remarcado bien: las «cosas públicas», aquellas que pertenecían a un pueblo, como el mar, no podían ser adquiridas apelando a una dudosa posesión acreditaba por el transcurso de los años. ${ }^{52}$ Desde la más temprana ocupación de la tierra, así como los pueblos tenían el derecho de cazar, también tenían el derecho de pescar en su propio río, señalaba Grocio. $^{53}$

47 Freitas, 1925 [1625], 151-158.

48 Ibidem, 156.

49 Idem

50 Bosbach, 1997.

51 Grocio, 1979 [1609], 119-138.

52 Ibidem, 120.

53 Ibidem, 121, 133-138 
Este sin lugar a dudas era el flanco más débil de toda la disputa de Freitas contra Grocio por la libertad y el derecho de navegar y comerciar en las Indias orientales, y precisamente por ello prefirió solucionarla de una manera autoritaria y mucho menos dialogante. Es decir, otorgando en dicha disputa el máximo poder a la autoridad real. Según Freitas, «cuantos doctores exigen prescripción inmemorial para adquirir el mar suponen que el soberano goza de igual derecho» que todos los hombres. Sin embargo, «esto no es aplicable a los soberanos que no están sometidos al emperador u otro príncipe temporal, pudiendo afirmar por tanto que cuando uno de tales soberanos se apropia y vindica para sí le basta la ocupación previa y su determinación». ${ }^{54}$

\section{Conclusiones}

En la particular refutación de Serafín de Freitas a la tesis de Hugo Grocio sobre el derecho de todos los pueblos al libre navegar y comerciar por los mares y océanos de las Indias orientales pesó mucho su formación de canonista, y desde ese campo del saber poco se podía hacer para frenar la deriva comercial a la que se veían obligadas y arrastradas las repúblicas (Holanda) y monarquías (Inglaterra) más punteras de este momento. El «dominio de los mares» - así lo refleja la cita de Walter Raleigh que abre este trabajo- era la almendra o clave de bóveda para dominar el comercio, obtener riqueza y ponerse a la cabeza del mundo. España y Portugal, unidas durante algo más de medio siglo gracias a una mezcla de azar, conquista y realpolitik, pero actuando ante los ataques holandeses e ingleses en sus posesiones de Asia como si fueran «siameses unidos por la espalda», decidieron reafirmarse en su tradición de pensamiento «político propio» y hacer oídos sordos a los buenos y sabios consejos que en la dirección apuntada por Raleigh les proporcionaban competentes y leales súbditos como Diego Sarmiento y Acuña (1567-1626), primer conde de Gondomar y embajador de España en Inglaterra entre 1613 y 1622. Para Diego Sarmiento y Acuña, testigo de los cambios que se estaban produciendo en la Inglaterra de Jacobo I, no había alternativa posible: «quien es hoy señor del mar también lo es de la tierra», subrayaba en 1616 en una importante carta a Felipe III de España (II de Portugal). ${ }^{55}$

54 Freitas, 1925 [1625], 273, y en general todo el capítulo VIII.

55 Elliott y De la Peña, 1978, 142. La expresión «siameses unidos por la espalda» la he tomado prestada de la reseña que Pablo Fernández Albaladejo realizó del libro de Jean-Frédéric Schaub Le Portugal au temps du comte-duc d'Olivares (2001) para Revista de Libros, 67-68, julio-agosto 2002. 
La huella intelectual de Serafín de Freitas fue muy distinta, y la podemos encontrar, aunque con importantes matices de método y presentación, en autores contemporáneos suyos como Juan de Solórzano y Pereira (15751654), cuyo célebre tratado De indiarum iure (1629) es la primera tentativa de exposición jurídica de conjunto sobre las razones de la presencia de los españoles en los territorios americanos. O en Domingos Antunes Portugal, autor algo posterior a Solórzano, pero que, con su Tractatus de donationibus iurium et bonorum regiae coronae (1673-1675), al igual que Freitas y otros autores en esta línea argumental, como Camilo Borrell, Benito Gil y Pedro Calixto Ramírez (1556-1627), daba total validez jurídica y moral a las donaciones papales de los territorios de América y Asia a los reyes de España y Portugal. ${ }^{56}$ Tales publicistas demuestran una lógica continuidad de pensamiento, distinta a la que otros destacados colegas y compatriotas estaban produciendo en sus territorios de origen y en el resto de Europa. El segundo tercio del siglo XVIII será un momento dulce para reverdecer las posturas tradicionales de este pensamiento «político propio» sobre la cuestión del derecho de propiedad del mar con obras como las de Pedro José Pérez Valiente (Dissertatio político-juridica de maris imperio, 1744), Ignacio José de Ortega y Cotes (Questiones del Derecho público en interpretación de los tratados de paces, 1747), Ramón Lázaro Dou (De Dominio Maris, 1765) y José de Olmeda y León (Elementos de Derecho público de la paz $y$ de la guerra, 1771). ${ }^{57}$

Aunque sin duda es cierto que la obra de Serafín de Freitas no tiene el peso ni la proyección político-intelectual de la de Hugo Grocio, sus argumentaciones sobre el poder del papa representan un punto remarcable, concordante también, como se ha mencionado, con esta cultura de pensamiento «político propio» que generó la monarquía de España durante los siglos XVI y XVII. ${ }^{58}$

Recibido el 29 de junio de 2015 Aceptado el 1 de diciembre de 2015

56 Merêa, 1924. Simó Santonja, 1973.

57 Herrero Rubio, 1952. Fernández Albaladejo, 2007, 245-286.

58 Maravall, 1944. Fernández Santamaría, 1986. Iñurritegui, 1998. Rodríguez de la Flor 1999. Fernández Albaladejo, 2007 (93-123) y 2009 (395-561). Ocupándose del importante momento transicional de «crisis de la conciencia europea», véase Martín Marcos, Iñurritegui y Cardim, 2015. 


\section{JOSÉ ANTONIO MARTÍNEZ TORRES}

\section{Referencias bibliográficas}

Alexandrowicz, Charles H.: «Freitas versus Grocio», en Armitage, David (ed.), Theories of Empire, 1450-1800, Londres, Ashgate-Variorum, 1998, 239-259.

Alloza, Ángel, «El contrabando en Portugal durante la primera mitad del siglo XVII. Las raíces económicas de un sentimiento antiespañol», en Martínez Shaw, Carlos y Martínez Torres, José Antonio (dirs.), España y Portugal en el Mundo, 1581-1668, Madrid, Polifemo, 2014, 61-87.

Armitage, David, Foundations of Modern International Thought, Cambridge, Cambridge University Press, 2013.

Baiāo, António, A censura literaria inquisitorial, Coimbra, Academia das Sciéncias de Lisboa-Imprensa da Universidade, 1919.

Barcia Trelles, Camilo, «Fray Serafín de Freitas y el problema de la libertad oceánica», Revista General de la Marina, 130, 1946, 331-348.

Bensabat Amzalak, Moses, Trois précurseurs portugais: Santarém et les assurances. Freitas et la liberté des mers. Veiga et les opérations de bourse, Paris, Librairie du Recueil Sirey, 1935.

Bethencourt, Francisco, La Inquisición en la época moderna. España, Portugal, Italia, siglos XV-XIX, Madrid, Akal, 1997.

Borschberg, Peter, The Portuguese and Free Trade in the East Indies, Singapur, NUS Press, 2011.

Bosbach, Franz, Monarchia universalis. Storia di un concetto cardine della política europea (secoli XVI-XVIII), Milán, Vita e Pensiero, 1997.

Bouza, Fernando, Filipe I de Portugal, Lisboa, Circulo de Leitores, 2005.

Boxer, Charles Ralph, A Índia portuguesa em meados do séc. XVII, Lisboa, Edições 70, 1982.

Boxer, Charles Ralph, «A Lutta Global com os Holandeses», en O Império marítimo portugués, 1415-1825, Lisboa, Ediçoes 70, 2001, 115-133.

Boxer, Charles Ralph, «The Portuguese in the East, 1500-1800», en Opera Minora, Lisboa, Fundação Oriente, III, 2002, 251-322.

Brett, Annabel S, Liberty, right and nature: Individual rights in later scholastic thought, Cambridge, Cambridge University Press, 1997.

Brito, Mónica, «Mare Liberum vs. Mare Clausum: Grotius, Freitas, and Selden's Debate on Dominion over the Seas», Journal of the History of Ideas, 64-3, 2003, 361-377.

Caetano, Marcelo, «Introduçao» en de Freitas, Serafín, Do Justo imperio asiático dos portugueses, traducción de Miguel Pinto Meneses, Lisboa, Instituto Nacional de Investigação Científica, 1983, 7-86.

Cardim, Pedro, Portugal unido y separado. Felipe II, la unión de territorios y el debate sobre la condición política del Reino de Portugal, Valladolid, Universidad de Valladolid, Cátedra Felipe II, 2014; prólogo de Jean-Frédéric Schaub. 
Carpintero Benítez, Francisco, Del derecho natural medieval al derecho natural moderno: Fernando Vázquez de Menchaca, Salamanca, Universidad de Salamanca, 1977.

Carro, Venancio, La teología y los teólogos-juristas españoles ante la conquista de América, Salamanca, Biblioteca de Teólogos españoles, 1944, 2 vols.

Clavero, Bartolomé, Historia del Derecho. Derecho Común, Salamanca, Universidad de Salamanca, 1994.

Crespo Solana, Ana, «Las rivalidades hispano-neerlandesas en el Pacífico y la conquista de Australia, de Cornelis de Houtman a Abel Janszoon Tasman (15951651)», Anuario de Estudios Americanos, 70-2, Sevilla, 2013, 479-507.

Disney, Anthony R., A decadencia do império da pimenta. Comercio portugués na Índia no início do séc. XVII, Lisboa, Edições 70, 1981.

Edwards, Charles S., Hugo Grotius: The Miracle of Holland, A Study of Political and Legal Thought, Chicago, Nelson Hall, 1981.

Elliott, John H., y De la Peña, José Francisco, Memoriales y cartas del Conde Duque de Olivares, Madrid, Alfaguara, 1978.

Elliott, John H, «Iberian Empires», en Scott, Hamish (ed.), The Oxford Handbook of Early Modern European History, 1350-1750, Oxford, Oxford University Press, Cultures \& Power, II, 2015, 200-226.

Emmer, Peter C., «The First Global War: The Dutch versus Iberia in Asia, Africa and the New World, 1590-1609», e-Journal Portuguese History, 1, 2003, $1-14$.

Fernández Albaladejo, Pablo, Materia de España, Madrid, Marcial Pons, 2007.

Fernández Albaladejo, Pablo, La crisis de la Monarquía, Madrid, Crítica-Marcial Pons, 2009.

Fernández Santamaría, José Antonio, Razón de Estado y política en el pensamiento español del Barroco (1595-1640), Madrid, Centro de Estudios Constitucionales, 1986.

Freitas, Serafín de, De Iusto Imperio Lusitanorum Asiatico, traducción de José Zurita, Valladolid, Imprenta de la Casa Social Católica, 1925 [1625].

García, Bernardo (dir.), Tiempo de paces. La Pax Hispanica y la Tregua de los Doce Años (1609-2009), Madrid, Fundación Carlos de Amberes, 2009.

Gelderen, Martin van, «From Domingo de Soto to Hugo Grotius: Theories of Monarchy and Civil Power in Spanish and Dutch Political Thought, 1555-1609», Il Pensiero Politico, 23-2, 1999, 182-206.

Gelderen, Martin van, «Hugo Grocio sobre la monarquía. Del rechazo republicano a la tolerancia con reservas», en García, Bernardo y Álvarez-Ossorio, Antonio (coords.), La monarquía de las naciones: patria, nación y naturaleza en la monarquía de España, Madrid, Fundación Carlos de Amberes, 2004, 765-776.

Gelderen, Martin van, «"Mare liberum”: Hugo Grocio, entre la defensa del colonialismo y los derechos de los "otros"», Pedralbes, 29, 2009, 195-212. 
Godinho, Vitorino Magãlhaes, «Os portugueses e a Carreira da Índia, 1497-1810», en Magãlhaes Godinho, Vitorino, Mito e mercadoria, utopia e prática de navegar. Séculos XVI-XVIII, Lisboa, Difel, 1990, 333-374.

Gómez Rivas, León M., «Influencia de Diego de Covarrubias en la obra de Hugo Grotius (Mare Liberum, 1609)», Procesos de Mercado, Revista Europea de Economía Política, X, 2, 2013, 321-341.

Grocio, Hugo, Epistolae, Amsterdam, P \& I Blaeu, 1687.

Grocio, Hugo, De Iure Praedae Commentarius, ed. H. G. Hamaker, The Hague, Martinus Nijhoff, 1868 [1604-1608].

Grocio, Hugo, De la libertad de los mares, traducción de V. Blanco García y Luis García Arias, Madrid, Centro de Estudios Constitucionales, 1979 [1609].

Grossi, Paolo, El orden jurídico medieval, Madrid, Marcial Pons, 1996.

Gruzinski, Serge, Les quatre parties du monde. Histoire d'une mondialisation, Paris, Éditions de La Martinière, 2004.

Haakonssen, Knud, Natural Law and Moral Philosophy: From Grotius to the Scottish Enlightenment, Cambridge, Cambridge University Press, 1996.

Herrero Rubio, Alejandro, Le Droit des Gens dans l'Espagne du XVIIIème siécle, Leiden, Collected Courses of the Hague Academy of International Law, 81, 1952, 309-450.

Hespanha, Antonio M., Cultura jurídica europea: síntesis de un milenio, Madrid, Tecnos, 2002.

Iñurritegui Rodríguez, José María, La gracia y la república: el lenguaje político de la teología católica y «El príncipe cristiano» de Pedro de Ribadeneyra, Madrid, UNED, 1998.

Israel, Johnatan I., La República holandesa y el mundo hispánico, 1606-1661, San Sebastián, Nerea, 1996.

Ittersum, Martine Julia van, «Hugo Grotius in Context, Van Heemskerck's Capture of the Santa Catarina and its Justification in De Jure Praedae (1604-1606)», Asian Journal of Social Science, 31-3, Leiden, 2003, 511-548.

Ittersum, Martine Julia van, Profit and Principle: Hugo Grotius, Natural Rights Theories and the Rise of Dutch Power in the East Indies, 1595-1615, Leiden, Brill, 2006.

Ittersum, Martine Julia van, «Mare Liberum Versus The Propriety of the Seas? The Debate between Hugo Grotius (1583-1645) and William Welwood (15521624) and its Impact on Anglo-Scotto-Dutch Fishery Disputes in the Second Decade of the Seventeenth Century», Edinburgh Law Review, 10-2, 2008, 239-276.

Ittersum, Martine Julia van, «Dating the Manuscript of De Jure Praedae (16041608): What watermarks, foliation and quire divisions can tell us about Hugo Grotius' development as a natural rights and natural law theorist», History of European Ideas, 35-2, 2009a, 125-193. 
Ittersum, Martine Julia van, «Preparing Mare Liberum for the Press. Hugo Grotius' Rewriting of Chapter 12 of De iure praedae in November-December 1608», en Blom, Hans W. (ed.), Property, Piracy and Punishment: Hugo Grotius on War and Booty in De iure praedae. Concepts and Contexts, Leiden, Brill, 2009b, 246-280.

Ittersum, Martine Julia van, «The long goodbye: Hugo Grotius' justification of Dutch expansion overseas, 1615-1645», History of European ideas, 36-4, 2010, 386-411.

Kahn, Ellison, The life and works of Hugo Grotius (1583-1645), Pretoria, South Africa Law Commission, 1983.

Lesaffer, Randall, «La Tregua de los Doce Años y la formación del Derecho de Naciones clásico», en García García, Bernardo (dir.), Tiempo de paces: La Pax Hispánica y la Tregua de los Doce Años, Madrid, Sociedad Estatal de Conmemoraciones Culturales/ Fundación Carlos Amberes, 2009, 177-193.

Lévesque de Burigny, Jean, Vie de Grotius, avec l'Histoire de ses ouvrages, Amsterdam, M. M. Rey, 1752, tomo 1.

Mann, Golo, «La guerra de los Treinta Años», en Mann, Golo y Heuss, Alfred (dirs.), Historia Universal. De la Reforma a la Revolución, Madrid, Espasa-Calpe, 1, 1988, 155-272.

Maravall, José Antonio, La teoría española del Estado en el siglo XVII, Madrid, Instituto de Estudios Políticos, 1944.

Mariño, Primitivo, «Minos seu mare tutum», Archivum Historicum Societatus Iesu, LXI-122, Roma, 1992, 309-337.

Martín Marcos, David; Iñurritegui, José María y Cardim, Pedro, Repensar a identidade. O mundo ibérico nas margens da crise da consciencia europeia, Lisboa, Centro de História d'Aquém e d'Além-Mar, 2015.

Martínez Shaw, Carlos y Martínez Torres, José Antonio (dirs.), España y Portugal en el Mundo, 1581-1668, Madrid, Polifemo, 2014.

Martínez Torres, José Antonio (ed.), «Conexiones imperiales. España y Portugal en América, África y Asia durante la Unión de Coronas», Melanges de la Casa de Velázquez, 2016, en prensa.

Merêa, Paulo, «Os jurisconsultos portugueses e a doutrina do "mare clausum"», Revista de Historia, 49, Lisboa, 1924, 5-23.

Miaja, Adolfo, «Las ideas fundamentales del Derecho de Gentes en la obra de Fray Serafín de Freitas», Anuario de la Asociación Francisco de Vitoria, V, 19321933, 171-201.

Murteira, André, A Carreira da Índia e o Corso Neerlandês, 1595-1625, Lisboa, Tribuna, 2012.

Murteira, André, «La Carreira da Índia y las incursiones neerlandesas en el Índico occidental, 1604-1608», en Martínez Shaw, Carlos y Martínez Torres, José Antonio (dirs.), España y Portugal en el Mundo, 1581-1668, Madrid, Polifemo, 2014, 299-314. 


\section{JOSÉ ANTONIO MARTÍNEZ TORRES}

Nussbaum, Arthur, Historia del Derecho Internacional, Madrid, Editorial Revista de Derecho Privado, 1949.

Nys, Ernest, Études de Droit International et de Droit Politique, Paris-Bruxelles, A. Castaigne, 1901.

Pagden, Anthony, La caída del hombre natural. El indio americano y los orígenes de la etnología comparativa, Madrid, Alianza Editorial, 1988.

Pagden, Anthony, Señores de todo el Mundo. Ideologías del Imperio en España, Inglaterra y Francia (en los siglos XVI, XVII y XVIII), Barcelona, Península, 1997.

Pagden, Anthony, «Commerce and Conquest. Hugo Grotius and Serafim de Freitas on the Freedom of the Seas», Mare Liberum, 20, 2000, 33-55.

Pagden, Anthony, La ilustración y sus enemigos. Dos ensayos sobre los orígenes de la modernidad, Península, Barcelona, 2002.

Pardo Tomás, José, Ciencia y censura. La Inquisición española y los libros científicos en los siglos XVI y XVII, Madrid, CSIC, 1991.

Pauw, Frans de, Grotius and the Law of the Sea, Bruxelles, Editions de l'Institut de Sociologie, 1965.

Pinto Crespo, Virgilio, Inquisición y control ideológico en la España del siglo XVI, Madrid, Taurus, 1983.

Placer López, Gumersindo, Fray Serafín de Freitas, mercedario jurisconsulto portugués, Madrid, Artes Gráficas, 1956.

Pocock, John G. A., Pensamiento político e historia. Ensayos sobre teoría y método, Madrid, Akal, 2011.

Raleigh, Walter, Judicious and Select Essays and Observations, London, AM, 1667 [1650].

Ramada Curto, Diogo, Cultura Imperial e Projetos Coloniais (séculos XV a XVIII), Campinas, Unicamp, 2009.

Rodríguez de la Flor, Fernando, La península metafísica. Arte, literatura y pensamiento en la España de la Contrarreforma, Madrid, Biblioteca Nueva, 1999.

Roelofsen, Cornelis Gerrit, «Grotius and the International Politics of the Seventeenth Century», en Bull, Hedley; Kingsbury, Benedict y Roberts, Adam (eds.), Hugo Grotius and International Relations, Oxford, Oxford University Press, 1992, 108-112.

Schaub, Jean-Frédéric, Le Portugal au temps du comte-duc d'Olivares (16211640). Le conflict de juridiction comme exercise politique, Madrid, Casa de Velázquez, 2001.

Schmitt, Carl, El nomos de la tierra en el Derecho de Gentes del Ius Publicum Europaeum, Madrid, Centro de Estudios Políticos y Constitucionales, 1979.

Schneewind, Jerome B., The Invention of Autonomy: a History of Modern Moral Philosophy, Cambridge, Cambridge University Press, 1998. 
Sherley, Anthony, Peso de todo el mundo (1622). Discurso sobre el aumento de esta Monarquía (1625), edición y estudios de Ángel Alloza, Miguel Ángel de Bunes y José Antonio Martínez Torres, Madrid, Polifemo, 2010.

Simó Santonja, Vicente Luis, Escuela portuguesa del derecho internacional. Siglo XVII: Domingos Antunes Portugal, Valencia, Sucesor de Vives Mora Artes Gráficas, 1973.

Skinner, Quentin, «Meanning and Understanding in the History of Ideas», History and Theory, 8, 1969, 489-509.

Solórzano Pereira, Juan de, Disputationem de Indiarum iure, Madrid, Tipografía Francisco Martínez, 1629.

Subrahmanyam, Sanjay, L'Empire portugais d'Asie, 1500-1700: Histoire économique et politique, Paris, Maisonneuve et Larose, 1999.

Tomás y Valiente, Francisco, Manual de Historia del Derecho Español, Madrid, Tecnos, 1986.

Usher, Abbott Payson, «The Growth of English Shipping, 1572-1922», Quaterly Journal of Economics, 42, 1928, 465-478.

Valladares, Rafael, La rebelión de Portugal, 1640-1680. Guerra, conflicto y poderes en la Monarquía Hispánica, Valladolid, Junta de Castilla y León, 1998.

Valladares, Rafael, Castilla y Portugal en Asia (1580-1668). Declive imperial y adaptación, Leuven, Leuven University Press, 2001.

Valladares, Rafael, La conquista de Lisboa. Violencia militar y comunidad política en Portugal, 1578-1583, Madrid, Marcial Pons, 2008.

Veen, Ernest van, An inquiry into the Portuguese decline in Asia, 1580-1645. Decay or Defeat?, Leiden, CNWS, 2000.

Welwood, William, An Abridgement of all the Sea Laws, London, Humfrey Lownes, 1613. 


\section{Anexo}

PRINCIPALES ENFRENTAMIENTOS ENTRE HOLANDA Y PORTUGAL EN LAS POSESIONES DEL ESTADO DA ÍNDIA (1595-1625)

1595 Salida del puerto de Amsterdam de las primeras flotas holandesas con rumbo a las Indias orientales doblando el Cabo de Buena Esperanza.

1597 Ataques holandeses en el suroeste de la India; primer establecimiento en Java.

1599 Ocupación holandesa de la isla de Banda.

1602 Fundación de la VOC (20 de marzo).

1603 André Furtado de Mendoza asume la capitanía de Malaca después de expulsar a los holandeses; bloqueo naval de Goa. Apresamiento de la carraca Santa Catarina (25 de febrero). Fundación del Conselho da Índia (25 de julio).

1604 Ataque holandés a Mozambique. Felipe III de España (II de Portugal) ordena que los navíos comerciales lleven suficientes piezas de artillería a bordo.

1604-1627 Sucesivas tentativas de ataques holandeses a Macao.

1605 Conquista holandesa de las islas de Amboina y Tidore.

1606 Bloqueo de Goa.

1609 Inicio de la Paz de Amberes. Publicación en Leiden de Mare Liberum de Hugo Grocio. Establecimiento de la primera factoría mercantil holandesa en Japón.

1617 Los portugueses son expulsados de Japón por influencia holandesa.

1618 Conflictos luso-holandeses en Ceilán, Sumatra y Malaca.

1619 La VOC instala su cuartel general en Batavia.

1621 Fin de la Tregua de Doce Años o Paz de Amberes.

1622 Tentativa de conquista de Macao.

1623 Bloqueo de Goa.

1625 Publicación en Coimbra de la obra de Serafín de Freitas: De iusto imperio lusitanorum asiático.

Fuente: Saturnino Monteiro, Batalhas e Combates da Marinha Portuguesa, Lisboa, Livreria Sá da Costa, 1995, vols. IV, V, VI (años 1580-1668). 